\section{KẾT LUẬN}

Sau đôt quy thiếu máu não cấp, tỉ suất tử vong tích lũy tại thời điểm 1 năm là 19,8\%. Các yếu tố liên quan độc lập với tử vong sau đột quy thiếu máu não cấp bao gồm tuổi lớn, tình trạng hôn nhân (ly thân, ly hôn, chồng/vợ mất), rung nhĩ, đường huyết lúc nhập viện, viêm phổi và lấp mạch từ tim.

\section{TÀI LIỆ THAM KHẢO}

1. K. C. Chang, M. C. Tseng, T. Y. Tan, et al.(2006),"Predicting 3-month mortality among patients hospitalized for first-ever acute ischemic stroke", J Formos Med Assoc. 105(4), pp. 310-7.

2. D. Chaudhary, A. Khan, S. Shahjouei, et al.(2021),"Trends in ischemic stroke outcomes in a rural population in the United States", J Neurol Sci. 422, pp. 117339.

3. A. A. Dabilgou, A. Dravé, J. M. A. Kyelem, et al.(2020),"Frequency and Mortality Risk Factors of Acute Ischemic Stroke in Emergency
Department in Burkina Faso", Stroke Res Treat. 2020, pp. 9745206.

4. Z. Liu, W. Lin, Q. Lu, et al.(2020),"Risk factors affecting the 1-year outcomes of minor ischemic stroke: results from Xi'an stroke registry study of China", BMC Neurol. 20(1), pp. 379.

5. K. Nedeltchev, N. Renz, A. Karameshev, et al.(2010),"Predictors of early mortality after acute ischaemic stroke", Swiss Med Wkly. 140(1718), pp. 254-9.

6. G. W. Petty, R. D. Brown, Jr., J. P. Whisnant, et al.(2000),"Ischemic stroke subtypes : a population-based study of functional outcome, survival, and recurrence", Stroke. 31(5), pp. 1062-8.

7. J. Putaala, S. Curtze, S. Hiltunen, et al.(2009),"Causes of death and predictors of 5year mortality in young adults after first-ever ischemic stroke: the Helsinki Young Stroke Registry", Stroke. 40(8), pp. 2698-703.

8. G. Saposnik, M. D. Hill, M. O'Donnell, et al.(2008),"Variables associated with 7-day, 30day, and 1-year fatality after ischemic stroke", Stroke. 39(8), pp. 2318-24.

\title{
CÁC YẾU TỐ LIÊN QUAN ĐẾN BIẾN ĐỔI HUYẾT ÁP TRONG QUÁ TRÌNH LOQC MÁU Ở BỆNH NHÂN BỆNH THÂ̂N MẠN GIAI ĐOẠN CUỐI CHẠY THẦn NHÂN TẠO CHU KỲ
}

\section{TÓM TẮT}

Mục tiêu nghiên cứu: Nghiên cứu một số yếu tố liên quan đến biến đổi huyết áp trong quá trình lọc máu ở bệnh nhân bệnh thận mạn giai đoạn cuối chạy thận nhẩn tạo chu k̀̀y. Phương pháp nghiên cứu: nghiên cứu mô tả cắt ngang được thực hiện trên 119 bềnh nhân đang chay thận nhân tao chu kỳ̀ tai Bệnh viện đa khoa 115 Nghệ An. Kết quả: Qua nghiên cứu 714 ca lọc ở 119 bệnh nhân cho thấy: (1) 20,2\% ca lọc máu có tăng huyết áp và $15,8 \%$ ca lọc có hạ huyết áp; (2) Nhóm bệnh nhân trên 50 tuổi, tỷ lệ hạ huyết áp là $57,5 \%$ và tỷ lệ tăng huyết áp là $57,3 \%$ cao hơn nhóm bệnh nhân < 50 tuổi; nhóm bệnh nhân tăng trên $3 \mathrm{~kg}$ giữa 2 lần lọc máu có tỷ lệ hạ huyết áp cao nhất là 53,9\%; nhóm bệnh nhân chạy thận nhân tạo tốc độ siêu lọc $>750 \mathrm{ml} / \mathrm{h}$, có nồng độ ure, creatinin máu cao, albumin máu thấp có nguy cơ bị hạ huyết áp trong khi lọc máu cao hơn. Sự khác biệt có ý nghĩa thống kê với $p<0,05$. Kết luận: Sự biến đối huyết áp trong quá trình lọc máu ở bệnh nhân bệnh thận mạn giai đoạn cuối chạy thận nhẩn tạo chu kỳ có liển quan đến các yếu tố: tuổi $>50$, trọng lượng cơ thể tăng trên 3 kg giữa 2 lần lọc máu, tốc độ siêu lọc,

*Trường Đại Học Y Khoa Vinh

Chịu trách nhiệm chính: Nguyễn Văn Tuấn

Email: tuanminh1976@gmail.com

Ngày nhận bài: 9.3.2021

Ngày phản biện khoa học: 7.5.2021

Ngày duyệt bài: 12.5.2021

\section{Nguyễn Văn Tuấn, Hoàng Thị Hoài}

nồng độ ure, creatinin máu cao và nồng độ albumin máu thẩp.

Tư khóa: Biến đổi huyết áp; chạy thận nhân tạo chu kỳ.

\section{SUMMARY \\ THE FACTORS RELATED TO CHANGERS OF BLOOD PRESSURE DURING \\ HEMODIALYSIS IN PATIENTS WITH END- STAGE RENAL DISEASE}

Objectives of the study: To study the factors related to changes of blood pressure during hemodialysis in patients with ESRD. Research methodology: cross-sectional descriptive study. Results: Survey 714 times of dialysis in 119 patients shows that: (1) $20,2 \%$ of dialysis had hypertension and $15,8 \%$ of dialysis had hypotension; (2) In the group of patients over 50 years old, the rate of hypotension was $57,5 \%$ and the rate of hypertension was $57,3 \%$, that is higher than the group of patients $<50$ years old; the group of patients who gained more than $3 \mathrm{~kg}$ between 2 dialysis times had the highest rate of hypotension that was 53,9\%; the group of patients on hemodialysis with ultrafiltration rate $>750$ $\mathrm{ml} / \mathrm{h}$, the concentration of blood ure and creatinine are high and the concentration of blood albumin is low that have a higher risk of hypotension while on dialysis $(p<0.05)$. Conclusion: The variation of blood pressure during dialysis in patients with ESRD is related to: age $>50$ years, increased body weight by 
more than $3 \mathrm{~kg}$ between dialysis sessions, the ultrafiltration rate, the concentration of blood ure and creatinine are high and the concentration of blood albumin is low.

Key words; Changes in blood pressure; Hemodialysis.

\section{I. ĐĂT VẤN ĐỀ}

Hiện nay trên toàn thễ giới ước tính có khoảng 2 triệu người mắc bệnh thận mạn giai đoạn cuối và số bệnh nhân được chẩn đoán mắc bệnh này tiếp tục tăng ở mức 5-7\% mỗi năm. Điều trị thay thế thận cho bệnh thận mạn giai đoạn cuối có 3 phương pháp: Ghép thẩn, loc màng bụng và thận nhân tạo. Trong đó lọc máu chu kỳ chiếm tỷ lệ $90 \%$ tổng số bệnh nhân lọc máu (bao gồm thận nhân tạo theo chu kỳ và lọc màng bung) [4].

Kỹ thuật lọc máu cũng như máy móc thiết bị đã có nhiểu tiến bộ đáng kể giúp cải thiện tỷ lệ sống sót, kéo dài tuổi thọ cũng như chất lượng sống của bệnh nhân. Mặc dù vậy, nhưng tỷ lệ tử vong của bênh nhân mắc bệnh thận mạn giai đoạn cuối vẫn còn cao, vì nhóm bệnh nhân này có nguy cơ mắc bệnh tim mạch cao hơn so với dân số nói chung. Khoảng $50 \%$ số ca tử vong của bệnh thận mạn giai đoạn cuối do nguyên nhân tim mạch [8]. Các biến cố tim mạch hay xảy ra trong quá trình lọc máu được cho do biến đổi huyết áp trong cuộc lọc, bao gồm hạ huyết áp và tăng huyết áp. Biến đổi huyết áp là nguyên nhân chính gây tử vong ở bệnh nhân bệnh thận mạn giai đoạn cuối.

Xuất phát từ vấn đề trên, chúng tôi tiến hành nghiên cứu đề tài này với mục tiêu: Nghiên cứu một số yếu tố liên quan đến biến đổi huyết áp trong quá trình lọc máu ở bệnh nhân bệnh thận mạn giai đoạn cuối chạy thận nhân tạo chu kỳ.

\section{II. ĐỐI TƯợNG VÀ PHƯƠNG PHÁP NGHIÊN CỨU \\ 1. Đối tượng nghiên cứu}

1.1. Đối tượng. Bệnh nhân bệnh thận mạn giai đoạn cuối chạy thận nhân tạo chu kỳ tại Khoa thận nhân tạo - Bệnh viện đa khoa 115 Nghệ An.

\subsection{Tiêu chuẩn lựa chon.}

- Tuổi và giới: Bệnh nhân từ 16 tuổi trở lên, thuộc cả 2 giới nam và nữ. Bệnh nhân được chẩn đoán bệnh thận mạn giai đoạn cuối - theo phân loại của KDIGO 2012, chạy thận nhân tạo chu kỳ 3 lần/1 tuần.

- Bệnh nhân đồng ý tham gia nghiên cứu.

\subsection{Tiêu chuẩn loại trừ:}

- Bệnh nhân đang có bệnh lí cấp tính: nhiễm khuẩn, nhồi máu cơ tim cấp, đột quỵ não.

- Bệnh nhân suy tim nặng, rối loạn nhịp tim nặng
- Bênh nhân rối loạn tâm thần và ý thức.

\section{Phương pháp nghiên cứu}

2.1. Thiết kế nghiên cứu : Nghiên cứu mô tả cắt ngang.

2.2. Cỡ mẫu: Chọn toàn bộ 119 bệnh nhân bệnh thận mạn giai đoạn cuối chạy thận nhân tạo chu kỳ tại Khoa thận nhân tạo - Bệnh viện đa khoa 115 Nghệ An đáp ứng tiêu chuẩn lựa chọn đối tượng nghiên cứu.

2.3. Phương pháp tiến hành.

2.3.1. Chuẩn bị người bệnh. Người bệnh đến lọc máu được hỏi tiền sử, khám lâm sàng, đo cân nặng trước và sau khi lọc máu. Trong đó chú ý theo dõi huyết áp vào các thời điểm: đo trước khi lọc máu 10 phút, trong khi lọc máu đo huyết áp định kỳ tại các thời điểm 60,120, 180 phút, sau lọc 10 phút và bất kỳ thời điểm nào có các triệu chứng lâm sàng của biến đổi huyết áp.

2.3.2. Chuẩn bị phương tiện và máy móc. Máy thân nhân tạo 4008S Fresenius, hê thống nước RO, dịch lọc bicacbonat, huyết áp kế thủy ngân.

\subsubsection{Kỹ thuât tiến hành:}

- Kỹ thuật lọc máu: tiến hành lọc máu chu kỳ theo quy chuẩn của Bộ Y Tế Việt Nam năm 2018.

- Kỹ thuật đo huyết áp:

+ Chuẩn bị bệnh nhân: để bệnh nhân nằm trên giường thận nhân tạo, cởi bỏ quần áo chặt, bộc lộ cánh tay bên không có shunt tay, để tay thả lỏng, không nói chuyện trong khi đo.

+ Dụng cụ: sử dụng huyết áp kế thủy ngân.

+ Cách đo và ghi nhận giá trị HA: dùng băng quấn tay đạt tiêu chuẩn. Băng quấn đặt ngang mức tim, mép dưới băng quấn trên nểp khuỷu tay $3 \mathrm{~cm}$. Đo 2 lần, cách nhau ít nhất 2 phút, lấy trị số trung bình của 2 lần đo.

\section{Các tiêu chuẩn đánh giá}

3.1. Tiêu chuẩn đánh giá giai đoạn bệnh thân mạn. Chẩn đoán giai đoạn bệnh thận mạn dựa trên mức lọc câu thận theo KDIGO năm 2012.

3.2. Tiêu chuẩn đánh giá biến đổi huyết áp trong cuộc lọc máu:

- Theo K/DOQI, hạ huyết áp là giảm huyết áp tâm thu $\geq 20 \mathrm{mmHg}$ hoặc giảm huyết áp động mạch trung bình $10 \mathrm{mmHg}$ so với trước cuộc lọc kèm với các biểu hiện lâm sàng: hoa mắt, chóng mặt, buồn nôn, nôn, mệt, ngất xỉu...

- Tăng huyết áp trong ca lọc máu:

+ Huyết áp trung bình tăng $\geq 15 \mathrm{mmHg}$ trong ca lọc máu hoặc ngay sau khi kết thúc lọc máu so với huyết áp ngay trước khi bắt đầu lọc hoặc

+ Huyêt áp tâm thu tăng $\geq 10 \mathrm{mmHg}$ trong ca lọc so với huyết áp ngay trước khi bắt đâuu lọc.

3.3. Phương pháp xử lý số liệu. Các số 
liệu thu được nhập vào phần mềm Ecxel xử lý theo phương pháp thống kê y học sử dụng phần mềm SPSS 20.0.

- Sử dụng ANOVA test để so sánh trung bình các quan sát nếu biến có phân bố chuẩn.

- Sử dụng test X2 để so sánh sự khác biệt về tỷ lệ phần trăm.

\section{KẾT QUẢ VÀ BÀN LUẬN}

4.1. Đặc điểm chung của đối tượng nghiên cứu

Bảng 1. Đặc điểm chung của đôi tượng nghiên cứlu.

\begin{tabular}{|c|c|c|c|}
\hline Chỉ số & $\bar{x} \pm S D$ & $n$ & $\%$ \\
\hline $\begin{array}{c}\text { Nhóm tuối } \\
<50 \\
>50\end{array}$ & \multirow[t]{2}{*}{$\begin{array}{c}46,75 \pm \\
15,06\end{array}$} & $\begin{array}{l}79 \\
47\end{array}$ & $\begin{array}{l}60,5 \\
39,5\end{array}$ \\
\hline Tống & & 119 & 100 \\
\hline $\begin{array}{l}\text { Thời gian lọc máu } \\
\text { chu kỳ (năm) }\end{array}$ & \multirow{3}{*}{$\begin{array}{c}3,96 \pm \\
2,99\end{array}$} & & \\
\hline $\begin{array}{l}\text { < } 1 \text { năm } \\
\mathbf{1}-\mathbf{3} \text { năm } \\
\text { 3- } 5 \text { năm } \\
>5 \text { năm }\end{array}$ & & $\begin{array}{l}21 \\
\mathbf{4 0} \\
33 \\
25\end{array}$ & $\begin{array}{l}17,6 \\
33,6 \\
27,7 \\
21,1\end{array}$ \\
\hline Tống & & 119 & 100 \\
\hline
\end{tabular}

Nhận xét: Tuối trung bình của nhóm bệnh nhân nghiên cứu là $46,75 \pm 15,06$ tuổi, tuổi thấp nhất là 19 tuổi và tuổi cao nhất là 75 tuổi, nhóm tuổi dưới 50 là độ tuổi chủ yếu ở bệnh nhân lọc máu chiếm $60,5 \%$. Thời gian lọc máu 1- 3 năm chiếm tỷ lệ cao nhất là $33,6 \%$ và có thời gian lọc máu trung bình là 3,96 $\pm 2,99$ năm.
4.2. Các yếu tố liên quan đến sự biến đổi huyêt áp trong ca loc máu.

Bảng 2. Tỷ lệ biến đổi huyết áp trong ca loc máu

\begin{tabular}{|c|c|c|}
\hline $\begin{array}{c}\text { Tình trạng biến đối } \\
\text { HA }\end{array}$ & $\begin{array}{c}\text { Số ca lọc } \\
\text { máu }\end{array}$ & $\begin{array}{c}\text { Tỷ lệ } \\
\text { \% }\end{array}$ \\
\hline Tăng HA & 144 & 20,2 \\
\hline Hạ HA & 113 & 15,8 \\
\hline Không biến đối HA & 457 & 64,0 \\
\hline Tống & $\mathbf{7 1 4}$ & $\mathbf{1 0 0}$ \\
\hline
\end{tabular}

Nhận xét: Qua 714 lần lọc máu của 119 bệnh nhân cho thấy có $20,2 \%$ ca lọc có tăng huyết áp và $15,8 \%$ ca lọc có hạ huyết áp.

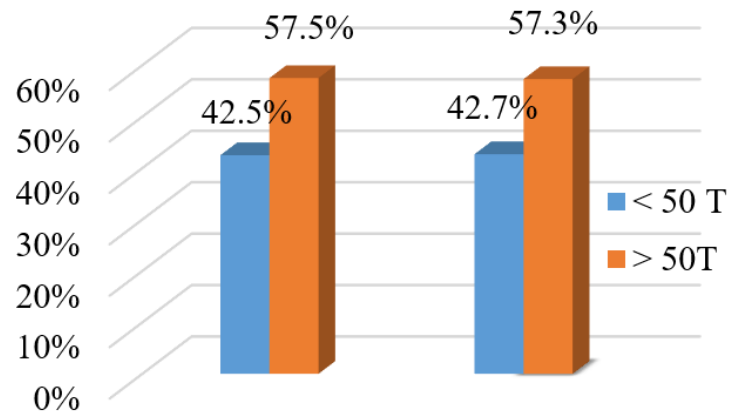

Hạ HA Tăng HA

\section{Biểu đồ 1. Môí liên quan giữa biên đổi HA} và nhóm tuổi.

Nhận xét: Nhóm bệnh nhân > 50 tuổi chiếm tỷ lệ cao hơn ở các ca có biến đổi huyết áp trong quá trình lọc máu so với nhóm bệnh nhân $<50$ tuổi $(p<0,05)$.

Bảng 3. Môi liên quan giữa sự biến đổi huyêt áp với mức tăng cân giữa 2 kỳ lọc của bệnh nhân TNTCK.

\begin{tabular}{|c|c|c|c|c|c|c|c|}
\hline & \multirow{2}{*}{$\begin{array}{c}\text { Tăng cân giữa } \\
2 \text { kỳ LM }\end{array}$} & \multicolumn{2}{|c|}{ Hă HA } & \multirow[b]{2}{*}{$\mathbf{p}$} & \multicolumn{2}{|c|}{ Tăng HA } & \multirow[b]{2}{*}{$\mathbf{p}$} \\
\hline & & Số lân & Tỷ lệ (\%) & & Số lần & Tỷ lệ (\%) & \\
\hline 1 & $<1 \mathrm{~kg}$ & 2 & 1,8 & \multirow{4}{*}{$\begin{array}{l}\mathrm{p}_{2-4}<0,05 \\
\mathrm{p}_{3-4}<0,05\end{array}$} & 3 & 2,1 & \multirow{4}{*}{$\begin{array}{c}p> \\
0,05\end{array}$} \\
\hline 2 & $1,0-2,0 \mathrm{~kg}$ & 16 & 14,2 & & 42 & 29,2 & \\
\hline 3 & $2,1-3,0 \mathrm{~kg}$ & 34 & 30,1 & & 65 & 45,1 & \\
\hline 4 & $>3,0 \mathrm{~kg}$ & 61 & 53,9 & & 34 & 23,6 & \\
\hline & Tống & 113 & 100 & & 144 & 100 & \\
\hline
\end{tabular}

Nhận xét: Nhóm bệnh nhân hạ huyết áp có mức tăng cân trên 3kg chiếm tỷ lệ cao nhất là $53,9 \%$, nhóm tăng cân từ $1-2 \mathrm{~kg}$ chiểm 30,1\%, sự khác biệt có ý nghĩa thống kê giữa 2 nhóm.

Đối với nhóm bệnh nhân THA về mức tăng cân giữa 2 kỳ lọc thì nhóm tăng 2-3 kg chiếm tỷ lệ cao nhất là $45,1 \%$ và nhóm tăng trên $3 \mathrm{~kg}$ chiếm $23,6 \%$ và chúng tôi không tìm thấy mối liên quan nào giữa mức tăng cân giữa 2 kỳ lọc với bệnh nhân THA.

Bảng 4. Mối liên quan giữa biển đổi HA và tốc độ siêu lọc.

\begin{tabular}{|c|c|c|c|c|c|}
\hline Tốc độ siêu lọc & $\begin{array}{c}\text { Ca loc không biến } \\
\text { đổi HA }(n, \%)\end{array}$ & $\begin{array}{c}\text { Ca loc Ha HA } \\
(n, \%)\end{array}$ & $\mathbf{p}$ & $\begin{array}{l}\text { Ca loc tang } \\
\text { HA }(n, \%)\end{array}$ & $\mathbf{p}$ \\
\hline $\begin{array}{l}\text { Tốc độ siêu } \\
\text { lọc } \leq 750 \mathrm{ml} / \mathrm{h}\end{array}$ & $292(69,19 \%)$ & $44(10,43 \%$ & \multirow{2}{*}{$\begin{array}{c}\mathrm{p}< \\
0,005\end{array}$} & $86(20,38 \%)$ & \multirow{2}{*}{$\begin{array}{l}\mathrm{p}> \\
0,05\end{array}$} \\
\hline $\begin{array}{l}\text { Tốc đô̂ siêu } \\
\text { lọc > } 750 \mathrm{ml} / \mathrm{h}\end{array}$ & $165(56,51 \%)$ & $69(23,63 \%$ & & $58(19,86 \%)$ & \\
\hline
\end{tabular}

Nhận xét: Nhóm bệnh nhân có tốc độ siêu lọc > 750ml/h thường có nguy cơ hạ huyết áp hơn. 
Bảng 5. So sánh hemogloboin và hematocrit trước lọc ở nhóm bệnh nhân có biến đổi HA và không biến đổi HA.

\begin{tabular}{|c|c|c|c|c|c|}
\hline Chi số & Không biến đối HA(1) & Hạ HA (2) & p & Tăng HA(3) & p \\
\hline $\mathrm{Hb}\left({ }^{x} \pm \mathrm{SD}\right)$ & $94,15 \pm 16,8$ & $80,31 \pm 19,81$ & $\mathrm{p} 1,2<0,05$ & $99,68 \pm 14,46$ & $\mathrm{p} 1,3>0,05$ \\
\hline $\mathrm{Hct}\left({ }^{(x} \pm \mathrm{SD}\right)$ & $0,29 \pm 0,05$ & $0,24 \pm 0,06$ & $\mathrm{p} 1,2<0,005$ & $0,32 \pm 0,04$ & $\mathrm{p} 1,3>0,05$ \\
\hline
\end{tabular}

Nhận xét: Nhóm bệnh nhân có ha huyết áp trong quáa trình lọc máu có nồng độ Hemoglobin và HCT thấp hơn nhóm khồng có biến đổi huyết áp trong quá trình lọc máu $(p<0,05)$.

Bảng 6. So sánh chỉ số albumin, creatinin, ure trước lọc máu của bệnh nhân biến đổi huyêt áp và không biến đổi huyết áp.

\begin{tabular}{|c|c|c|c|c|c|}
\hline Chỉ số & $\begin{array}{l}\text { Không biến } \\
\text { đổi HA (1) }\end{array}$ & $\begin{array}{c}\text { Ha HA } \\
(2)\end{array}$ & $\mathbf{p}$ & $\begin{array}{c}\text { Tăng HA } \\
\text { (3) }\end{array}$ & $\mathbf{p}$ \\
\hline $\begin{array}{c}\text { Albumin máu }(g / l) \\
\left(\bar{x}_{ \pm S D}\right)\end{array}$ & $34,78 \pm 2,62$ & $32,51 \pm 3,08$ & $\mathrm{p} 1,2<0,05$ & $\begin{array}{c}36,40 \pm \\
1,33\end{array}$ & $\mathrm{p} 1,30,05$ \\
\hline $\begin{array}{c}\text { Ure máu (mmol/l) } \\
\left(\begin{array}{l}X^{\prime} \\
\pm S D)\end{array}\right.\end{array}$ & $21,67 \pm 5,82$ & $26,51 \pm 3,03$ & 05 & $\begin{array}{c}22,01 \pm \\
6,19 \\
\end{array}$ & $\mathrm{p} 1,3$ \\
\hline $\begin{array}{c}\text { Creatinin máu } \\
(\mu \mathrm{mol} / \mathrm{l})(\overline{\mathrm{x}} \pm \mathrm{SD})\end{array}$ & $\begin{array}{c}778,21 \pm \\
216,94 \\
\end{array}$ & $\begin{array}{c}967,09 \pm \\
185,13 \\
\end{array}$ & $\mathrm{p} 1,2<0,05$ & $\begin{array}{c}790,30 \pm \\
223,79 \\
\end{array}$ & $\mathrm{p} 1,3>0,05$ \\
\hline
\end{tabular}

Nhân xét: Nhóm bệnh nhân có ha huyết áp trong cuộc loc có nồng độ albumin máu thấp hơn và nồng độ ure, creatinin máu cao hơn nhóm không có biến đổi huyết áp $(p<0,05)$.

Bảng 7. So sánh một số chỉ số điện giải trước lọc máu của bệnh nhân biến đổi HA và không biến đổi HA.

\begin{tabular}{|c|c|c|c|c|c|}
\hline $\begin{array}{c}\text { Điện giả đồ } \\
\text { máu (mmol/I) }\end{array}$ & $\begin{array}{c}\text { Không biến } \\
\text { đối HA }\end{array}$ & Tăng HA & $\mathbf{p}$ & Hạ HA & p \\
\hline $\mathrm{Na}^{+}\left(\mathrm{x}_{ \pm} \mathrm{SD}\right)$ & $133,63 \pm 2,84$ & $133,71 \pm 2,26$ & $\mathrm{p} 1,3<0,05$ & $133,84 \pm 3,03$ & $\mathrm{p} 1,3<0,05$ \\
\hline $\mathrm{Ca}^{+}\left(\mathrm{x}_{ \pm} \mathrm{SD}\right)$ & $1,12 \pm 0,11$ & $1,16 \pm 0,12$ & $\mathrm{p} 1,3>0,05$ & $1,16 \pm 0,10$ & $\mathrm{p} 1,3>0,05$ \\
\hline $\mathrm{K}^{+}\left(\mathrm{x}_{ \pm} \mathrm{SD}\right)$ & $4,14 \pm 1,59$ & $4,80 \pm 0,63$ & $\mathrm{p} 1,3>0,05$ & $4,29 \pm 0,86$ & $\mathrm{p} 1,3>0,05$ \\
\hline
\end{tabular}

Nhận xét: Không có sự khác biêt có ý nghĩa thống kê nồng độ $\mathrm{Na}^{+}, \mathrm{Ca}^{+}, \mathrm{K}^{+}$giữa nhóm có biến đổi huyết áp và nhóm không biến đổi huyết áp.

\section{BÀN LUÂN}

Trong nghiên cứu của chúng tôi, nhóm bệnh nhân hay gặp biến đổi HA là từ nhóm 50 tuổi trở lên. Với tỷ lệ hạ huyết áp cao nhất ở nhóm bệnh nhân lớn hơn 50 tuổi là $57,5 \%$ và tỷ lê THA chiếm tỷ lệ cao nhất ở nhóm bệnh nhân lớn hơn 50 tuổi là $57,3 \%$. Sự khác biệt có ý nghĩa thống kê về tần suất biến đổi huyết áp giữa nhóm bé hơn tuổi và lớn hơn 50 tuổi với $p<0,005$. Kooman và cộng sự ghi nhận bệnh nhân hạ huyết áp xảy ra thường xuyên ở $44 \%$ số người bênh tuổi trên 65 và 32\% ở nhóm tuổi dưới 45 tuổi [6]. Các nghiên cứu đều chỉ ra rằng ha huyết áp thường gặp với tỷ lệ cao hơn ở nhóm người cao tuổi, bởi người cao tuổi thường bị các bênh tim mạch kèm theo, đây là yếu tố nguy cơ dẩn đến ha huyết áp trong loc máu. Bên canh đó người cao tuổi sự đàn hồi của thành mạch kém và nhiêu bệnh lý kèm theo nên cũng dế bị tăng huyết áp trong ca loc máu.

Trong nghiên cứu của chúng tôi đối với nhóm bệnh nhân hạ huyết áp có mức tăng cân trên 3 kg chiếm tỷ lệ cao nhất là $53,9 \%$, nhóm tăng cân từ $1-2 \mathrm{~kg}$ chiếm $30,1 \%$, sự khác biệt có ý nghĩa thống kê giữa 2 nhóm. Thống kê của tác giả Cù Tuyết Anh cho thấy nhóm bệnh nhân tăng trên $4 \mathrm{~kg}$ có tỷ lệ hạ huyết áp cao chiếm $17,2 \%$ trên tất cả các ca lọc máu trong nhóm trên 4kg [1]. Bệnh nhân được tư vấn hạn chế ăn muối và qua đó tránh được tăng cân giữa hai lần chạy thận $(<1 \mathrm{~kg} / \mathrm{ngày})$. Hạn chế ăn muối có hiệu quả hơn nhiều trong việc giảm tăng cân giữa hai lần chạy thận so với giảm uống nước. Đối với nhóm bệnh nhân tăng huyết áp về mức tăng cân giữa 2 kỳ lọc của nghiên cứu chúng tôi thì nhóm tăng 2-3 kg chiếm tỷ lệ cao nhất là $45,1 \%$ và nhóm tăng trên $3 \mathrm{~kg}$ chiếm $23,6 \%$ và chúng tôi không tìm thấy mối liên quan nào giữa mức tăng cân giữa 2 kỳ lọc với bệnh nhân tăng huyết áp. Kết quả nghiên cứu của chúng tôi cho thấy, nhóm bệnh nhân có tốc độ siêu lọc > $750 \mathrm{ml} / \mathrm{h}$ thường có nguy cơ hạ huyết áp hơn. Theo nghiên cứu của Đỗ Văn Tùng cho thấy nếu như đặt tốc độ siêu lọc cao $1250 \mathrm{ml} / \mathrm{h}$ thì thường có tình trạng hạ huyết áp ngay từ giờ đầu hoặc giờ thứ 2 [3].

Thiếu máu là hội chứng thường gặp ở những bệnh nhân bệnh thận mạn giai đoạn cuối. Chúng tôi đã tiến hành so sánh lượng hemoglobin trung bình và hematocrit trung bình của giữa 3 nhóm trên thì chỉ số ở nhóm hạ huyết áp thấp hơn hẳn so với nhóm không biến đổi HA, sự khác biệt có 
ý nghĩa thống kê. Nghiên cứu của Đỗ Văn Tùng cũng thống kê được 67 lần lọc máu có hạ huyết áp, hàm lượng hemoglobin và hematocrit trung bình trước lọc lần lượt là 79,8 $\pm 22,1 \mathrm{~g} / \mathrm{l}, 0,25 \pm$ $0,06 \mathrm{l} / \mathrm{I}$ thấp hơn nhóm không biến đổi $\mathrm{HA}(93,2$ $\pm 18,4 \mathrm{~g} / \mathrm{l} ; 0,29 \pm 0,05 \mathrm{l} / \mathrm{l})$, sự khác biệt có ý nghĩa thống kê[3]. Theo Bregman và cộng sự thiếu máu là một trong những yếu tố nguy cơ của hạ huyết áp trong cuộc lọc. Kết quả nghiên cứu của một số tác giả nghiên cứu cho thây truyền máu có tác dụng giảm tần suất tụt huyết áp trong lọc máu và theo tác giả Palmer khuyên nên điều trị thiếu máu dùng erythropoietin để duy trì hematocrit $>0,3 \mathrm{l} / \mathrm{l}$ như một biện pháp phòng ngừa hạ huyết áp.

Kết quả nghiên cứu của chúng tôi cho thấy nhóm hạ huyết áp hàm lượng albumin trung bình là $32,51 \pm 3,08 \mathrm{~g} / \mathrm{l}$ thấp hơn so với nhóm không biến đổi huyết áp, sự khác biệt có ý nghĩa thống kê $\mathrm{p}<0,05$. Nghiên cứu của tác giả Nguyễn Thị Thu Hải cũng cho thấy nhóm hạ huyết áp có hàm lượng albumin trung bình là $36,1 \pm 7,3 \mathrm{~g} / \mathrm{l}$ thấp hơn nhóm không biến đổi huyết áp là $38,8 \pm 7,1 \mathrm{~g} / \mathrm{l}$, và sự khác biệt có ý nghĩa thống kê. Qua các nghiên cứu về mức độ albumin trong cuộc lọc máu thì theo tác giả Knoll thì nguy cơ hạ huyết áp cao ở những bệnh nhân có áp lực keo thấp chính vì vậy sử dụng albumin trong điều trị hạ huyết áp đã được chứng minh là có hiệu quả [7]. Đối với nhóm bệnh nhân tăng huyết áp, kết quả nghiên cứu cho thấy hàm lượng albumin là $36,40 \pm 1,33 \mathrm{~g} / \mathrm{l}$ cao hơn nhóm không biến đổi huyết áp là $34,78 \pm 2,62 \mathrm{~g} / \mathrm{l}$ và sự khác biệt này có ý nghĩa thống kê $\mathrm{p}<0,05$. Nhưng kết quả lại ngược với các nghiên cứu về albumin máu của Inrig [5] ở bệnh nhân THA có nồng độ albumin máu thấp hơn và tác giả Nguyễn Văn Ngọc [2] lại cho thấy nồng độ Albumin trung bình trong máu cao hơn có liên quan đến THA. Như vậy sự liên quan giữa albumin và THA chưa thật sự chắc chắn. Nên cần phải có nhiều nghiên cứu hơnn nữa để khẳng định lại vấn đề này.

Kết quả ở bảng 6 cho thấy đối với nhóm bênh nhân hạ huyết áp, nồng độ ure trung bình 26,51 $\pm 3,03 \mathrm{mmol} / \mathrm{l}$ và creatinin $967,09 \pm 185,13$ $\mu \mathrm{mol} / \mathrm{l}$ đều cao hơn so với nhóm không biến đổi HA $(21,67 \pm 5,82 \mathrm{mmol} / \mathrm{l}$ và $778,21 \pm 216,94$ $\mu \mathrm{mol} / \mathrm{I})$, sự khác biệt có ý nghĩa thống kê với $\mathrm{p}<$ 0,005 . Điều này được Bregman giải thích rằng nông độ ure có vai trò quan trọng trong chênh lệch lực thẩm thấu trong và ngoài tế bào. Khi ure bị lấy ra khỏi dịch ngoại bào nhanh quá trong quá trình lọc máu, sự chênh lệch áp lực thẩm thấu sẽ làm cho dịch từ ngoài tế bào chuyển vào trong tế bào dẫn tới giảm thể tích huyết tương hạ huyết áp [1]. Đối với nhóm bệnh nhân tăng huyết áp kết quả nghiên cứu của chúng tôi cho thây không có mối liên quan cả ure và creatinin trước lọc so với nhóm bênh nhân không biến đổi huyết áp. Sự khác biệt về điện giải của các nhóm biến đổi huyết áp với nhóm không biến đổi huyết áp hầu như không có ý nghĩa thống kê. Chỉ thấy kali máu trước lọc của nhóm bệnh nhân tăng huyết áp $(4,80 \pm 0,63$ $\mathrm{mmol} / \mathrm{l})$ cao hơn rõ với nhóm bệnh nhân không có biến đổi huyết áp $(4,14 \pm 1,59 \mathrm{mmol} / \mathrm{l})$, sự khác biệt có ý nghĩa thống kê $\mathrm{p}<0,05$.

\section{KẾT LUÂNN}

Sự biến đổi huyết áp trong quá trình lọc máu ở bệnh nhân bệnh thận mạn giai đoạn cuối chạy thận nhân tạo chu kỳ có liên quan đến các yểu tố: tuổi > 50, trọng lượng cơ thể tăng trên $3 \mathrm{~kg}$ giữa 2 lần lọc máu, tốc độ siêu lọc, nồng độ ure, creatinin máu cao và nồng độ albumin máu thấp.

\section{TÀI LIẸU THAM KHẢO}

1. Cù Tuyết Anh (2004 ), "Nhận xét tỉ lệ biến chứng và các yếu tố nguy cơ của tụt huyết áp trong loc máu chu kỳ ở bệnh nhân suy thận mạn giai đoạn cuối", Luận văn tốt nghiệp chuyên khoa cấp İI, Trường Đại Học Y Hà Nội.

2. Nguyễn Văn Ngọc (2015), Khảo sát tình trang tăng huyết áp trong ca lọc máu ở bệnh nhân thận nhân tao chu kỳ tại bệnh viện hữu nghị Việt Đức, Luân vằn thạc sỹ y học, Trường đai hoc Y Hà Nội.

3. Đố Văn Tùng (2010), Nghiên cứu biến chứng tụt huyết áp trong lọc máu chu kỳ ở bệnh nhân suy thận mạn giai đoạn cuối tại bệnh viện trung ương đa khoà Thái Nguyên, Luận văn thạc sỹ y học, trường đại học y khoa Thái N guyên.

4. Bernadette Thomas, Sarah Wulf, Boris Bikbov et at (2015), Maintenance Dialysis throughout the World in Years 1990 and 2010, J Am Soc Nephrol; 26(11): 2621-2633.

5. Inrig J.K, U. D. Patel, R. D. Toto, et al (2009), Association of blood pressure increases during hemodialysis with 2-year mortality in incident hemodialysis patients: a secondary analysis of the Dialysis Morbidity and Mortality Wave 2 Study, Am J Kidney Dis, 54(5), 881-890.

6. Kooman JK. et al. (2007), " EBPG guideline on haemodynamic instability",NephrologyDialysis Transplantation, vol. 22, pp. 22-44.

7. Knoll G. et al. (2004), "A Randomized, Controlled Trial of Albumin versus Saline for the treatment of Intradialytic Hypotension", Journal of American Society Nephrology, vol. 15, pp. 487- 492.

8. Rosario Cianci, Silvia Lai, Laura Fuiano et al, (2009), Hypertension in Hemodialysis. An Overview on Physiopathology and Therapeutic Approach in Adults and Children, The Open Urology \& Nephrology Journal; 2, 11-19. 